\title{
$>$ Ano de cães danados
}

\author{
$>$ A stray-dog year
}

por Davi Alexandre Tomm

Doutorando em Letras na UFRGS, na linha de pesquisa Teoria, Crítica e Comparatismo. Bolsista CAPES. E-mail: tomm.davi@gmail.com. ORCID: 0000-0001-5713-0701.

\section{por Guilherme Mautone}

Doutorando em Filosofia na UFRGS, com pesquisa em Filosofia da Arte e Estética sobre a questão das definições de arte, intencionalismo, contextualismo e arte contemporânea. Bolsista CAPES. E-mail: guimautone@gmail.com. ORCID: 0000-0001-8623-6230.

\section{por Lauro Iglesias Quadrado}

Professor Colaborador no curso de Letras - Inglês na Universidade Estadual do Paraná. Doutor em Letras, Literaturas de Língua Inglesa, pela UFRGS. E-mail: lauroiq@gmail.com. ORCID: 0000-0002-8272-0073.

\section{por Patrícia Cristine Hoff}

Professora no Instituto Federal Sul-rio-grandense. Doutoranda em Letras na UFRGS, na linha de pesquisa Teoria, Crítica e Comparatismo. E-mail: patriciacristine.hoff@gmail.com. ORCID: 0000-0001-9910-7892.

\section{por Paula Trusz}

Doutoranda em Artes Visuais junto ao PPGAV/UFRGS, na área de História, Teoria e Crítica. E-mail: paulatrusz@gmail.com. ORCID: 0000-0002-5700-1245.

Chegamos ao segundo número da repaginada Revista PHILIA | Filosofia, Literatura \& Arte. Em outubro de 2019, momento absolutamente inclemente para a produção científica no Brasil, nos encontramos em estado de triste celebração com nossa segunda editoração.

Já em nossa primeira publicação, no começo do ano, expressávamos em nosso texto de apresentação nossa inquietante tarefa como editores de um periódico dedicado às humanidades. Em posição de poder, a dificultar e a tentar bloquear o acesso e a produção de arte e conhecimento científico, não há mais um 
vampiresco Marcus Brutus ${ }^{1}$, cruel e atormentado, receoso de seus antigos fantasmas, espectros de sua própria ação desleal; o novo abantesma shakespeariano a fazer sua aparição e assombrar a nação toma a forma de Claudius $^{2}$, tirano e inapto, ele mesmo um rei denunciado pelos fantasmas de sua violência.

Não coincidentemente, a fantasmagoria dá a tônica dos assaltos cometidos pela linguagem - tristemente não só por ela, por mais que se queira sustentar o indefensável que é a violência institucionalizada - do que há de podre na cúpula de nosso reino. É simbólico que a obsessão contra a intelectualidade e a ciência comprometida, e contra grupos e indivíduos indesejáveis parta de uma ameaça paranoica e injustificada através de políticas simplistas, reducionistas e persecutórias.

No ano de 1848, longínquo apenas cronologicamente, já se escrevia sobre a "Santa Caçada" a um certo espectro que rondava a Europa. ${ }^{3}$ Nesta segunda década dos anos 2000 vivemos também em um estado atormentado; sua constituição é de desmesurado alerta, em manifestação de coletivo assombro. $O$ Brasil tem sua convivência social em forma de hauntology - haunt ("assombrar" em inglês) + ontologia, o cotidiano assustado. Diria Mark Fisher ${ }^{4}$ que "nada usufrui de uma experiência puramente positiva. Tudo que existe é possível somente com base em uma grande série de ausências".

O desejo pelo apagamento é maior do que o desejo de afirmação ou de qualquer ideia propositiva: o arrocho desejado assume o disfarce de contingenciamento necessário, sua atividade-fim a destruição; a criação de ausências como política de estado, a batalha cultural. Assombração: "eventos que

\footnotetext{
${ }^{1}$ Cf. William Shakespeare, Julius Caesar, 2000.

${ }^{2}$ Cf. William Shakespeare, Hamlet, 2000.

${ }^{3}$ Karl Marx \& Friedrich Engels, Manifesto do partido comunista, 2001, p. 21.

${ }^{4}$ Mark Fisher, Ghosts of my life, 2014, p. 61. Tradução nossa. Trecho original: "nothing enjoys a purely positive existence. Everything that exists is possible only on the basis of a whole series of absences."
} 
não aconteceram de fato, futuros que falharam em materializarem-se e permaneceram espectrais". 5

Se por um lado há o medo construído com a ameaça espectral do diferente, por outro lado a névoa, a bruma noir que deveria ocultar os instintos brutais está manifesta, feito filme de Kurosawa: sempre à espreita mas à vista plena, há um cão danado embebido de amor divino à procura de sangue. ${ }^{6}$ Se a milícia noir pretende dominar a paisagem cultural com seus leais funcionários do crime, cães adestrados para o terror que fariam Hannah Arendt escrever um novo tratado7, vamos atrás das riquezas da incerteza, como posto por Enrique Vila-Matas": "E a névoa? Essa, por outro lado, sempre esteve entre as coisas que mais me fascinaram no mundo. Houve vezes em que tive a impressão de que tudo estava nela, na névoa".

Não será então o desanimador panorama cultural, dominado por discussões públicas que beiram e atingem a barbárie com frequência quase diária, capaz de esconder a existência de um número enorme de pesquisadores em meio a tantas cortinas de fumaça. A "inquietude constante" das "forças escondidas" na bruma ${ }^{9}$ faz unir um grupo crítico e contrário ao desmanche de nações intentado por forças que se assumem superiores.

Resta encontrar, em meio às incertezas muitas vezes etéreas e impalpáveis, maneiras de combater alguns fantasmas históricos de violência que assombram com frequentes aparições. Que os textos a seguir sejam formas de tateio em busca de alternativas.

A Revista PHILIA | Filosofia, Literatura \& Arte conta com uma coleção variada de artigos que passeiam pelos mais diversos temas interseccionais de

\footnotetext{
${ }^{5}$ Ibidem, p. 273. Tradução nossa. Trecho original: "events that had not actually happened, futures that failed to materialise and remained spectral."

${ }^{6}$ Cf. Akira Kurosawa (Dir.), Cão Danado, 1949.

${ }^{7}$ Cf. Hannah Arendt, Origens do totalitarismo, 2012.

${ }^{8}$ Enrique Vila-Matas, Não há lugar para a lógica em Kassel, 2015, p. 129.

${ }^{9}$ Ibidem, p. 128.
} 
nosso periódico. Com muito gosto, apresentamos brevemente os autores e os textos nos parágrafos abaixo.

Alisson Cruz Soledade traz sua contribuição para o periódico com 0 comentário sobre videoclipes de rap em seu Uma Sutil Diferença: narrativas carcerárias em videoclipes de rappers brasileiros apenados e não apenados (1997 - 2000). A crescente produção e o destaque das várias manifestações do hiphop no Brasil são contemplados com o artigo, que foca tanto no histórico do movimento quanto na produção audiovisual de seus artistas, que frequentemente trazem o sistema prisional como tema central de seus problemas.

Alisson Preto Souza, em Estudos Culturais, Estudos Literários e Discussão Pós-Colonial: refletindo sobre o pensamento crítico, recupera os Estudos Culturais no âmbito dos estudos literários e propõe uma discussão sobre diferentes formas de argumentação e enunciação. Com isso, o autor debate a organização do cânone e as funcionalidades de linguagem envolvidas na disputa por formas de discurso e crítica, refletindo sobre o possível papel transformador da literatura em âmbitos culturais.

Com De Paisagens Escritas e Paisagens Pintadas: vínculos conceituais entre a pintura de Hipólito Caron e o romance Inocência de Alfredo Taunay, Ana Carla de Brito faz um exercício de vinculação conceitual entre produção literária e produção pictórica. A autora traça um histórico de relações que tomam forma de maneiras próximas, porém ambivalentes, que se revelam expandidas nos objetos específicos de pesquisa indicados no título do artigo.

Buscando também relações além-palavras, mas agora com objetos, Fercho Marquéz-Elul se ocupa de trazer o escrito e o textual para o ampliamento de experiências artísticas como um todo. Leviatã. o boato como elemento intersticial entre objeto e sujeito trata do boato, do rumor, como forma de parecença da frágil materialidade da obra escultórica e do objeto físico. 
Já Ângela Brandão traz uma discussão de fôlego acerca da figura do artista na construção de narrativas da História da Arte. A autora passeia por diferentes épocas que, marcadas por seus característicos estilos e gostos, foram ressignificando o papel do artista em si como núcleo dessas variadas formas de histórias. $\mathrm{O}$ artigo se chama Anotações sobre a Centralidade do Artista na história da arte.

Em texto idiossincrático, Antônio Carlos Sobrinho comenta o Brasil de 2019: Sobre Lampejos ou Tempos de Chumbo, ou, Por uma Comunidade de Vaga-lumes, ou, O que Pode a Arte? O autor encontra na arte uma prática que promove possibilidades de presença, trocas e encontros; a experiência artística como forma clínica, nos sentidos de Suely Rolnik, servindo para o combate da sensação de impotência e derrota. O histórico de violência de nosso país é recuperado pelo autor, que o contextualiza em nosso ambiente social e político contemporâneo.

Rumando para a filosofia, chegamos ao próximo artigo, Oralidade, Escrita e Estilo em Platão e Montaigne, de Bruno Alonso. O autor trata sobre a crítica de Platão à escrita, passando do comentário sobre os diálogos do filósofo grego para tratar dos ensaios de Montaigne, marcados pela oralidade e pela complicação da forma dialógica. $\mathrm{O}$ artigo levanta questionamentos e provocações sobre o estilo ensaístico do autor francês.

César Lopes Gemelli propõe uma expansão de possibilidades de leituras do filme Whisky em Existential isolation in Whisky (2004), reading uruguayan cinema beyond the concept of Small Cinema. O autor combate paradigmas constantemente repetidos pela crítica, que evita a análise do longa em si, não tocando em itens cinematográficos essenciais como fotografia e enquadramento, em detrimento do impulso pela categorização do filme como um expoente do small cinema, resultando em observações protocolares. 
A ironia no trabalho fotográfico de Carlos Pasquetti, de Cláudio Barcellos Jansen Ferreira, traz uma leitura do retrato, considerando a História da Arte e também Kierkegaard e seus entendimentos da ironia. $\mathrm{O}$ autor do artigo analisa o trabalho de Pasquetti desde sua concepção até sua execução final, com atenção a suas potencialidades simbólicas.

Na sequência, é a partir do conceito de Faërie que Fabian Quevedo da Rocha analisa a obra fantástica de J. R. R. Tolkien em Approaching Faërie: a study of J. R. R. Tolkien's on fairy stories. $\mathrm{O}$ artigo foca na criação da fantasia e de mundos secundários, e comenta o posicionamento de Tolkien em relação a suas bases em Cura, Escape e Consolo.

A produção e a circulação independentes dos zines e suas temáticas de relevância cultural estão no centro de Literature from the margins: a study on the relevance of zines. Fernanda Martinez Tarran e Nathalia Rodrigues de Carvalho analisam três zines brasileiros, defendendo a importância desse tipo de publicação na luta pela manutenção de ideais democráticos e de lutas minoritárias.

Fernando Bruno Antonelli Molina Benites e Mauricio Cesar Menon recuperam As Viagens de Gulliver, de Jonathan Swift. A análise de seu narrador em A vida de Gulliver entre os Houyhnhnms e a visão de Paulo: ser um Yahoo (humano) é ter um espinho na carne? é contextualizada pelos autores a partir do que fora colocado por Paulo em sua Segunda carta aos Coríntios, recorrendo ao crítico Northrop Frye e seu reconhecimento de intertextos bíblicos.

Indo ao cinema, temos no artigo de Fernando Valenzuela Carlucci, Gender \& perspective in Scarlet Street, um recorrido crítico sobre o filme noir e seus temas recorrentes. O autor do artigo logo se ocupa, a partir de seu embasamento crítico e psicanalítico, de buscar as conexões sobre as identidades de gênero das personagens do filme e noções como gênero e agência. 
Igor Corrêa de Barros examina A concepção relacional do poder em Foucault e a omissão da valoração ética. Para isso, apresenta elementos centrais do próprio Foucault e sua fortuna crítica desenvolvida por Andrew Sayer. O autor do artigo termina por analisar a obra foucaultiana em conjunto com Sayer, prolongando a relevância das questões levantadas pelo crítico.

O artigo Notas sobre a influência platônica em Michelangelo, de Laura Elizia Haubert, explora as relações entre as obras do jovem Michelangelo e a influência teórica do platonismo e neoplatonismo que se disseminaram em Florença durante a época de Lorenzo, o Magnífico.

Chegamos à poesia com A escuta do amor, de orelha a orelha, de Lucas Cyrino. $\mathrm{O}$ autor propõe a apreciação multissensorial da obra de Eucanaã Ferraz via Merleau-Ponty e Alckmar Luiz dos Santos; seu foco na escuta e na própria anatomia da escuta - nunca desassociada dos demais sentidos - desenvolve a leitura crítica da poesia de Ferraz e traz importante contribuição também para os Estudos de Som nos estudos literários.

Também expandindo leituras, Manoela Sarubbi Henares Figueiredo trata da reimaginação da obra shakespeariana em meios audiovisuais. Blank Verse. a história e as histórias de William Shakespeare traduzidas em websérie trata das reinvenções criativas, tanto da obra do bardo como de outros autores elisabetanos, em diversas manifestações que tomam forma de experimentos literários expandidos, desafiando discursos históricos.

Maria Júlia Pereira estuda a paródia em Macunaíma, sobretudo em relação a Peri, personagem de José de Alencar. A autora contextualiza movimentos artísticos e literários, levando em consideração sua participação na ação paródica de Mário de Andrade. O artigo se chama Macunaíma: diálogo com o romantismo a partir da paródia de Peri.

Seguindo nos estudos da literatura brasileira, Paulo Augusto Nedel dá à música papel central em sua leitura de Jorge Amado em A dialética da música 
em Dona Flor e seus dois maridos. O autor do artigo atribui a Vadinho e Teodoro a relação dialética mencionada no título através de suas ligações musicais, representativas das caracterizações de cada um e da oposição entre os dois.

Em O conceito de inautenticidade no pensamento heideggeriano de Ser e tempo, Rafael Ribeiro Almeida e Rogério Tolfo se ocupam da obra de Martin Heidegger e de seu Dasein, o ser-aí. Os autores do artigo trazem diferentes modos de ser-no-mundo sob o Dasein, o que os leva a desenvolver a proposta de discussão sobre inautenticidade - sempre instigados pelo filósofo alemão.

Com foco na teoria literária, Rosemary Elza Finatti analisa a obra da escritora estadunidense Kate Chopin. A prosa poética de Kate Chopin: imagens líricas da noite e o descompasso do homem na orquestra de Deus recupera diversos autores para a análise, em close reading, do estilo de Chopin, em um passeio por diversas correntes dos estudos literários.

Ricardo Cortez Lopes e Yana de Lima Martinez centralizam o ateísmo como questão de análise para a obra do dramaturgo Dias Gomes. Os autores do artigo realizam Um estudo sobre três premissas do argumento ateu na peça $O$ berço do herói, de Dias Gomes.

Em Cinema e fotografia: as técnicas e suas ambiguidades em Benjamin, Flusser e Agambem, Sônia Campaner Miguel Ferrari faz um recorrido sobre as reflexões dos três nomes citados no título sobre mudanças técnicas e suas consequências tanto na produção quanto na recepção da arte.

Finalizando a seção de artigos, Thiago de Castro Leite propõe uma reflexão sobre $O$ domínio da arte no pensamento de Hannah Arendt. $O$ autor do artigo recupera as ideias de Arendt ligadas à linguagem artística como forma de compartilhamento de significados que possam ser compartilhados em sociedade.

Neste número da Revista PHILIA temos uma resenha: a obra As helenas de troia, ny, de autoria de Bernadette Mayer e traduzida por Mariana Ruggeri, é 
resenhada por Nicolas Ferreira Neves Jacintho e Renan Augusto Ferreira Bolognin.

Já na seção de traduções, temos dois textos: Juan Carlos Acosta versa em português o castelhano uruguaio de Horacio Quiroga em Três contos de morte de Horacio Quiroga; por sua vez, Thaís Fernandes dos Santos traz Cinco ensaios de The Philosophy of Style, de Herbert Spencer, junto com alguns comentários sobre a obra do polímata inglês.

Por fim, cabe à artista Letícia Lopes encerrar este volume, com seu ensaio visual Elogio ao Mistério: revelações de atelier. A artista traz um confronto entre a linguagem representativa e aquilo que pode ser revelado por misteriosas construções guiadas pela linguagem ou por insuspeitas aparições inesperadas.

Faz-se necessário reiterar o agradecimento pelas submissões de todos que confiaram suas produções a nós - autores publicados neste número ou não -, e também a toda a equipe que, voluntariamente, esteve envolvida nos mais diversos processos que envolvem a Revista PHILIA |Filosofia, Literatura \& Arte. Não sabemos se venceremos unidos ou distraídos, mas oferecemos nosso periódico com um desejo de que os textos aqui reunidos e selecionados para vocês, leitores, encontrem forma de minifesto ${ }^{10}$; que a leitura do trabalho de outros colegas pesquisadores seja valorizada, animadora e possibilite reflexões e proposições ao diálogo.

Com a certeza da apreciação de nossos leitores, dividimos aqui nosso esforço com todos vocês.

${ }^{10}$ Cf. Paulo Leminski, Distraídos Venceremos, 2017. 


\section{Referências}

ARENDT, Hannah. Origens do totalitarismo: Antissemitismo, imperialismo, totalitarismo. Trad. Roberto Raposo. São Paulo: Companhia das Letras, 2012.

CÃO DANADO. Akira Kurosawa (Dir.). Japão: Shintoho, 1949. 1 filme (122 min), son., p \& b, 35mm. Título original: Nora inu. Legendas em inglês.

FISHER, Mark. Ghosts of my life: Writings on depression, hauntology and lost futures. Winchester, RU: Zero Books, 2014.

LEMINSKY, Paulo. Distraídos venceremos. São Paulo: Companhia das Letras, 2017.

MARX, Karl; ENGELS, Friedrich. Manifesto do partido comunista. Trad. Sueli Tomazzini Barros Cassal. Porto Alegre: L\&PM, 2001.

SCLIAR, Moacyr. Mês de cães danados. Porto Alegre: L\&PM, S.d. E-book.

SHAKESPEARE, William. Hamlet. Nova Iorque: Hungry Minds, 2000.

SHAKESPEARE, William. Julius Caesar. Nova Iorque: Hungry Minds, 2000.

VILA-MATAS, Enrique. Não há lugar para a lógica em Kassel. Trad. Antônio Xerxenesky. São Paulo: Cosac Naify, 2015.

\section{Referência para citação deste editorial}

TOMM, D. A.; MAUTONE, G.; QUADRADO, L. I.; HOFF, P. C.; TRUSZ, P. Editorial - Ano de cães danados. Revista PHILIA |Filosofia, Literatura \& Arte, Porto Alegre, volume 1, número 2, p. ix - xviii , outubro de 2019. 